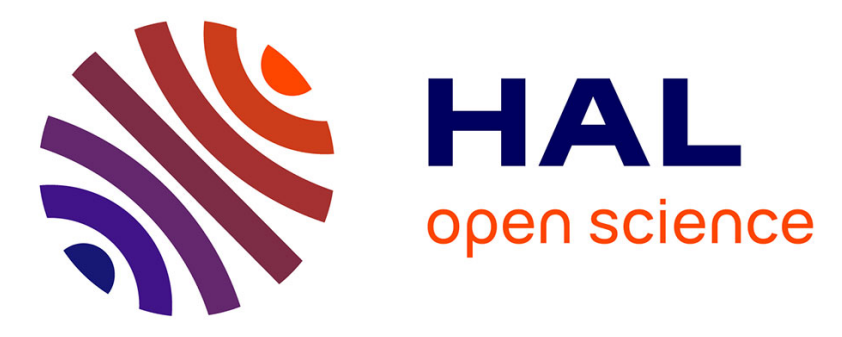

\title{
Substituting Computers for Mobile Phones? An Analysis of the Effect of Device Divide on Digital Skills in Brazil
}

Marcelo Araujo, Nicolau Reinhard

\section{- To cite this version:}

Marcelo Araujo, Nicolau Reinhard. Substituting Computers for Mobile Phones? An Analysis of the Effect of Device Divide on Digital Skills in Brazil. 11th International Conference on Electronic Participation (ePart), Sep 2019, San Benedetto Del Tronto, Italy. pp.142-154, 10.1007/978-3-03027397-2_12. hal-02446016

\section{HAL Id: hal-02446016 https://hal.inria.fr/hal-02446016}

Submitted on 20 Jan 2020

HAL is a multi-disciplinary open access archive for the deposit and dissemination of scientific research documents, whether they are published or not. The documents may come from teaching and research institutions in France or abroad, or from public or private research centers.
L'archive ouverte pluridisciplinaire HAL, est destinée au dépôt et à la diffusion de documents scientifiques de niveau recherche, publiés ou non, émanant des établissements d'enseignement et de recherche français ou étrangers, des laboratoires publics ou privés.

\section{(ㄷ)(i)}

Distributed under a Creative Commons Attribution| 4.0 International License 


\title{
Substituting Computers for Mobile Phones? An Analysis of the Effect of Device Divide on Digital Skills in Brazil
}

\author{
Marcelo Henrique de Araujo ${ }^{1[0000-0002-3853-966]}$ and Nicolau Reinhard ${ }^{10000-0003-1544-5523]}$ \\ ${ }^{1}$ University of São Paulo, School of Economics, Business and Accounting, \\ Av. Luciano Gualberto 908, São Paulo, SP 05508-101, Brazil \\ marcelo.haraujo@usp.br; reinhardeusp.br
}

\begin{abstract}
This paper aims to analyze the phenomenon of device divide in the Brazilian context in order to understand how different Internet access devices and sociodemographic factors influence the development of digital skills. The research uses the microdata of 2014 and 2016 editions of a Brazilian nationwide survey named ICT Households survey. The main findings show that mobile devices are widely used by Brazilian Internet users. However, while in upper classes this device plays the role of complementary access to other devices, allowing users to access the Internet using computer and mobile platforms, for lower-income groups mobile is the only means of Internet access, substituting the use of computer equipment. The results also demonstrate that Internet users who access the Internet using both computational and mobile devices exhibit the highest level of digital skills. In contrast, users connecting exclusively via mobile show lower levels of digital skills which might reduce their effectiveness in using the Internet. These outcomes show the relevance of understanding the conditions of Internet access as well as their implication for the development of digital skills and provision of Internet services.
\end{abstract}

Keywords: Digital Skills, Device Divide, Digital Inequalities, Digital Society.

\section{Introduction}

Internet access is increasing worldwide, with more than half the world population (51.2\%) using it, reaching a mark of approximately 3.9 billion Internet users [1]. Nevertheless, the question remains if this growth alone contributes to building an increasingly inclusive information society. Growth of internet usage varies between countries, as in developed nations, on average, four out of five people have access to the Internet, in developing countries this rate is approximately $47 \%$, showing that providing universal access to the Internet is still a significant challenge to these countries [1].

The first digital divide studies date back to the mid-nineties and focused exclusively on the dimension of material access to Information and Communication Technologies (ICT), with an emphasis on the dichotomous division between those who have access to the Internet and those who have not [2]. Investigations based on this approach are known as first-order digital divide [2,3]. However, from the 2000s on, this view of exclusion restricted to material access starts being challenged, since digital inequalities remained even after overcoming the Internet access barrier, such as differences in terms of the level of digital skills and/or engagement in ICT use. This group of studies is known as second- 
order digital divide $[3,4]$. Both the first and second order studies on digital divide show that Internet access, as well as the mastery of digital skills and Internet use, are unevenly distributed between Internet users based on different sociodemographic characteristics such as gender, age, geographic area, and social class. As a result, these sociodemographic factors are commonly classified as determinants of digital divide $[3,5,6]$.

Even with the widening of the debate on digital divide beyond material access to the Internet, understanding the effects of this dimension is still essential in order to qualify the Internet access, as well as to understand its implications in terms of the online experience [7]. With technological evolution and convergence, connecting to the Internet is no longer an activity restricted to computers, and can be performed by different devices (e.g. cell phones, TVs, game consoles, etc.), providing increasingly ubiquitous and mobile access $[7,8,9]$.

The relevance of the devices used for Internet access in the debate on digital divide is evidenced by the increase in the number of Internet users connected via mobile devices. In developing countries, these devices are a cost-effective Internet access option for lowincome users. However, even if mobile and computer devices can both provide access to the Internet, the types of devices used offer different online experiences, potentially impacting on the use of the Internet and on digital skills development [7,10], characterizing the existence of a device divide $[11,13]$.

Although this type of exclusion based on Internet access devices may have implications for the other levels of digital divide, few studies have empirically analyzed the effects of this device divide for the development of digital skills, especially in the context of developing countries. In this sense, this paper aims to delve into this phenomenon in order to highlight how different Internet access devices and sociodemographic factors influence the development of digital skills in a developing country such as Brazil. This research adopts a quantitative methodological approach using the microdata of the 2014 and 2016 editions of a nationwide survey called ICT Households survey, coordinated by the Regional Center for Studies on the Development of the Information Society (Cetic.br), which measures the ownership and use of Information and Communication Technologies by Brazilian citizens.

\section{$2 \quad$ Literature Review}

\subsection{Device Divide}

The diffusion of mobile Internet access is a subject of interest for both academics and policymakers, especially because of the potential role of leapfrogging due to this type of device. Mobile leapfrogging is the process by which new users obtain access to the Internet via mobile devices, without using traditional computer equipment such as the PC $[11,14]$. This issue has been the subject of intense debate, as some authors see this leapfrogging effect as beneficial, enabling a rapid and cost-effective reduction of Internet access gaps and also reducing the need for public policy interventions to deal with the persistent first-order digital divide [14]. On the other hand, a second group presents a critical view of this understanding, arguing that Internet access via mobile devices offers an inferior online experience $[7,10,11]$. 
In this debate on access devices, most studies have focused on the clash between mobile and computer equipment [7]. Devices such as mobile phones and smartphones offer advantages in convenience, more affordable pricing, mobility, continuous use of the internet (ubiquity), applications that use geolocation, games and streaming services $[7,15]$. However, even with technological developments, these devices are not entirely equivalent to computers, due to technical limitations: less memory, lower processing speed, smaller screen, limited typing capabilities. Those features make using the Internet more challenging and complex on the mobile platform, demanding a greater cognitive load on the part of the user [7,9,10,12].

The limitations on mobile affordances may also imply a reduction in the user's level of engagement, especially in activities that require content creation and/or information search [10]. The search for information tends to become a more superficial process and difficult to perform on mobile equipment, whereas on computers such activity tends to be more immersive, allowing a rich search and with more refined results [8]. Regarding creative activities, although they can be conducted on mobile devices, the elaboration of more complex content tends to be more easily performed on the computing platform [7]. While the use of computers favors online capital-enhancing activities, mobile devices are associated with specific activities such as leisure and entertainment and personal security $[7,9,8,13,31]$.

In summary, such findings suggest that mobile-only internet access may affect negatively the development of digital skills. Although few studies have explored this relationship, there is evidence that users of both mobile devices and computers tend to broaden their digital skills spectrum [10]. In this paper, the concept of device divide is operationalized by combining the different Internet access devices, segmenting users in: mobileonly Internet users; computer-only Internet users; and users that connect using both computer and mobile, named multiplatform users [13].

\subsection{Digital Skills}

Digital skills are defined as the ability to respond pragmatically and intuitively to the challenges and opportunities in exploiting the potential of the Internet and avoid frustrations in its use [16]. In this paper, the focus relies specifically on the skills required to use the Internet (Internet Skills) regardless of the equipment and/or technology employed. Therefore, specific device-dependent skills are not within the scope of the definition adopted $[3,6,24]$.

The first instruments developed to measure digital skills took a very limited view of this concept, i.e., considering only the basic and technical skills for using the Internet, such as the ability to use browser software, download and/or upload files [e.g. 4,17,18]. With the evolution of Internet use, researchers began to expand the understanding of digital skills, considering both the technical skills and content-related skills (those related to information search, communication and online content production) $[6,19,20,21,22,23]$. The digital divide literature presents a wide variety of proposals for measuring digital skills considering their specific domains/dimensions (e.g. communication, informational, creative). One of the main digital skills frameworks is based on the distinction between the purposes of the skills, that is, dividing between the technical skills necessary to use the Internet (medium-related skills) and those related to the content (content-related skills). 
Regarding technical skills, we highlight the following: (i) operational and (ii) formal skills, while considering the competences related to content, the following stand out: (iii) informational; (iv) communication; (v) content creation and (vi) strategic skills [24].

In this paper, digital skills will be measured considering four specific domains. The first refers to the operational skills, consisting of the technical and basic ability to operate the Internet, regardless of the type of device and equipment used. The second is the informational skills, the ability to search, select and evaluate the information identified. The third is the communication skills consisting of the ability to encode and decode messages and, consequently, to construct, understand and exchange meanings through Internet applications. Finally, the last domain involves content-creation skills the ability to create online content with acceptable levels of quality and to publish it online [24].

Empirical studies have shown the role of socioeconomic, generational, geographical and gender inequalities to explain the differences in the digital skills levels of Internet users $[2,5,6]$.

Regarding the relation between age and digital skills, the findings have been varied, with results that indicate positive and negative relationships between generational attribute and skills [6]. In general, studies suggest that younger Internet users have a greater ability to perform a large set of online activities, faster, more easily and more fluently, with lower levels of anxiety in the Internet use experience [4]. Although intuitive, some studies question this "superiority" of younger people in the use of the Internet, finding evidence that younger users are more competent only in technical-instrumental skills. On the other hand, in skills that demand information search and content evaluation, older users tend to perform better $[20,21,22,26]$.

The findings also point out that the level of education, as well as socioeconomic status (social class), have a positive relation with digital skills. In other words, the greater the socioeconomic status of the Internet users (related to schooling and income), the greater will be their level of digital competence [6,20,21,22].

There is no consensus in the literature about gender differences in relation to digital skills. Some authors point out that there is no distinction between genders concerning levels of digital competence [25]. However, others reinforce the stereotype based on gender, in which women are at a disadvantage in relation to the use of the Internet, due to aspects related to technological aversion and higher levels of technophobia, implying lower access rates and less capacity to use the web [27].

\section{$3 \quad$ Methodological Design}

Aiming at understanding the phenomenon of the device divide, as well as its implications on the levels of digital skills of Internet users in Brazil, this research uses the microdata of the ICT Households survey coordinated by Cetic.br. The ICT Households survey consists of a nationwide survey conducted annually since 2005 to measure the availability, possession and use of ICT by the Brazilian population aged 10 years and older [28]. In order to ensure international comparability, the design of this survey follows the set of guidelines and methodological definitions described in the Manual for Measuring ICT Access and Use by Households and Individuals, published by ITU [28]. Tables 1 and 2 present the set of ICT households survey variables used in this paper. 
In order to perform the data analysis, OLS regression (Ordinary Least Square) was used in order to demonstrate the effect of the different determinants of digital divide (e.g. geographic area, social class, age and gender) and Internet access devices on the domains of digital skills. This multivariate technique allows exploring the linear relationship in a set of explanatory variables with a metric dependent variable [29].

The first set of variables shown in Table 1 are the sociodemographic factors, that is, the personal and positional characteristics commonly considered to be determinants of the digital divide. Although the ICT households survey includes also other demographic attributes, for this research we selected only those that represent inequalities of geographical (area), generational (age), socioeconomic (social class and schooling) and gender, because they are the most frequently cited ones in the literature $[2,5]$.

Table 1. Demographic Factors and Device used to access Internet (variables)

\begin{tabular}{|c|l|l|}
\hline & Variables & Items/Scale \\
\hline \multirow{4}{*}{ Femographic } & Geographic Area & $1=$ Urban; $2=$ Rural. \\
\cline { 2 - 3 } & & $1=10$ to 15 years old. \\
& & $2=16$ to 24 years old. \\
& & $3=25$ to 34 years old. \\
& & $4=35$ to 44 years old. \\
& & $5=45$ to 59 years old. \\
& & $6=60$ years or older. \\
\cline { 2 - 3 } & Gender & $1=$ Male; $2=$ Female. \\
\cline { 2 - 3 } & Social Class & $1=$ Class A and B (higher classes) \\
& (Socioeconomic & $2=$ Class C (middle class) \\
& Status) & $3=$ Class D and E (working classes) \\
\hline \multirow{4}{*}{ access Internet } & Desktop & $1=$ Yes; $0=$ No. \\
\cline { 2 - 3 } & Laptop & $1=$ Yes; $0=$ No. \\
\cline { 2 - 3 } & Tablet & $1=$ Yes; $0=$ No. \\
\cline { 2 - 3 } & Mobile phone & $1=$ Yes; $0=$ No. \\
\cline { 2 - 3 } & Game Console & $1=$ Yes; $0=$ No. \\
\cline { 2 - 3 } & TV Set & $1=$ Yes; $0=$ No. \\
\hline
\end{tabular}

Source: ICT Household Survey 2014 and 2016 [28]

The geographical area consists of the location of the respondent's residence, which can be classified as urban or rural, according to the Brazilian Demographic Census. Urban areas are understood as cities (municipalities), villages (districts) or even isolated urban areas, while locations outside this boundary are classified as rural areas. The second variable represents the age group, with respondents of 10 years or more, followed by their gender. Social class represents the concept of socioeconomic status of respondents which is a composite indicator based on the level of education of the head of household, as well as the ownership of the household's durable goods (see [28]). In the published microdata of ICT Households survey, the respondents are classified into four social classes: A (highest), B, C and D and E (lowest). However, because of the low proportion of class A individuals in relation to the other classes, we chose to group classes $\mathrm{A}$ and $\mathrm{B}$, reducing this categorical variable to these three classes: A and B (group with greater economic power), $\mathrm{C}$ (middle class) and D and $\mathrm{E}$ (extract of lower economic power). 
Table 2 presents the items used to measure digital skills of the Internet user. Since the ICT Households survey does not have specific items and scales to measure this type of skills, these competencies are measured from a set of proxies with dichotomous scale that represent the activities carried out online by the Internet user in the last three months, as shown in table 2 . In line with the digital divide and digital literacy literature, which adopt the conceptualization of digital skills considering their specific domains/dimensions, leading to the following ones: (i) operational; (ii) informational; (iii) communication and (iv) content creation $[19,23,24]$. The operationalization of these four domains is given by the sum of the items corresponding to each of these domains.

Table 2. Items used to measure Digital Skills

\begin{tabular}{|cl|}
\hline Digital Skills & Dichotomous Items \\
\hline \multirow{3}{*}{ Operational } & Downloading films; \\
& Downloading songs; \\
& Downloading games; \\
& Downloading computer software, programs or applications. \\
\hline & Looking up information on products and services; \\
& Looking up information on health or healthcare services; \\
& Looking up information on travel and accommodations; \\
& Job searches or Sending resumes; \\
& Looking up information in virtual encyclopedia websites such as Wikipedia; \\
& Looking up information available in government agencies websites. \\
& Sending and receiving e-mails; \\
& Sending instant messages, such as chatting via Facebook, Skype or Whatsapp; \\
& Talking to people using programs such as Skype; \\
& Taking part in social networks sites, such as Facebook, Orkut or Google+; \\
& Participating in discussion lists or forums; \\
& Using microblogs, such as Twitter. \\
\hline \multirow{3}{*}{ Communication } & Sharing content on the Internet, such as texts, images or videos; \\
& Creating or updating blogs, Internet pages or websites; \\
& Posting personally created texts, images or videos on the Internet.
\end{tabular}

Source: ICT Household Survey 2014 and 2016 [28]

\section{Characterizing Brazilian Internet Users sample}

For the 2014 and 2016 editions of the ICT Households survey, respectively 19,221 and 20,772 individuals from urban and rural areas in Brazil were interviewed. Since this paper focuses specifically on Internet users, the analysis considered only those respondents who reported having used the Internet at least once in the last three months. Therefore, the sample of this paper is composed by 10,221 (2014) and 11,050 (2016) respondents.

Table 3 presents the demographic profile of the Internet user in Brazil, indicating a predominance of urban users, more than $90 \%$ of the sample in both years. This geographical inequality may be due to the scarcity of technological infrastructure available in the rural areas, limiting the provision of this type of service. Regarding age, the results show a concentration of Internet users in the three younger age groups (10 to 34 years), thus reinforcing generational inequality, with the percentage of Internet users being inversely 
proportional to the age of the respondent $[5,2,16]$. There is a certain balance in the distribution of male and female Internet users, with a higher proportion of women in both years. The distribution of Internet users among the social classes shows a concentration of users in class C (middle class). Between 2014 and 2016 there was an increase in the proportion of Internet users in the lower-income social classes (D and E). These results show the socioeconomic structural inequality, in which lower purchasing power leads to reduced possibility to afford computational devices and/or Internet connection services.

Table 3. Demographic profile of Brazilian Internet Users $\left(\mathrm{N}_{2014}=10,221 ; \mathrm{N}_{2016}=11,050\right)$

\begin{tabular}{|c|c|c|c|c|}
\hline & \multicolumn{2}{|c|}{2014} & \multicolumn{2}{|c|}{2016} \\
\hline & $\mathbf{N}$ & $\%$ & $\mathbf{N}$ & $\%$ \\
\hline \multicolumn{5}{|l|}{ Geographic Area } \\
\hline Urban & 9703 & 94.9 & 10283 & 93.1 \\
\hline Rural & 518 & 5.1 & 767 & 6.9 \\
\hline \multicolumn{5}{|l|}{ Age Groups } \\
\hline 10 to 15 years old. & 1118 & 10.9 & 1046 & 9.5 \\
\hline 16 to 24 years old. & 2426 & 23.7 & 2622 & 23.7 \\
\hline 25 to 34 years old & 2835 & 27.7 & 2999 & 27.1 \\
\hline 35 to 44 years old. & 1907 & 18.7 & 1896 & 17.2 \\
\hline 45 to 59 years old. & 1501 & 14.7 & 1854 & 16.8 \\
\hline 60 years or older & 434 & 4.2 & 633 & 5.7 \\
\hline \multicolumn{5}{|l|}{ Gender } \\
\hline Male & 4665 & 45.6 & 5115 & 46.3 \\
\hline Female & 5556 & 54.4 & 5935 & 53.7 \\
\hline \multicolumn{5}{|l|}{ Social Class } \\
\hline Class A and B (upper classes) & 4229 & 41.4 & 3840 & 34.8 \\
\hline Class C (middle class) & 5173 & 50.6 & 5936 & 53.7 \\
\hline Class D and E (working classes) & 819 & 8.0 & 1274 & 11.5 \\
\hline Total & \multicolumn{2}{|c|}{10221} & \multicolumn{2}{|c|}{11050} \\
\hline
\end{tabular}

Regarding the device divide, there was an increase in the percentage of users connecting to the Internet via mobile phones, reaching $93.7 \%$ in 2016. Simultaneously, there was a decrease in the use of computers as an Internet access device. While in 2014, respectively, $52.3 \%$ and $46 \%$ of respondents accessed the web via desktops and laptops, in 2016 these percentages dropped to $32.2 \%$ and $33.7 \%$. This trend is sustained when analyzing the combination of different Internet access devices, as between 2014 and 2016, the percentage of computer-only internet users dropped from $22 \%$ to only $6 \%$, while the number of mobileonly internet users doubled from $21 \%$ to $42 \%$. In this period there was also a reduction among multiplatform Internet users, reduced from $57 \%$ to $52 \%$. The growth in the use of mobile phones to access the Internet occurred in all social classes. However, while in classes A and B (upper classes) the percentage of multiplatform users remained stable ( $71 \%)$, with about $23 \%$ of Internet users accessing only via mobile phone, in classes D and E, the rate of mobile-only internet users jumped from $40 \%$ to $71 \%$, with only $22 \%$ of multiplatform users. This result suggests that in lower economic classes the mobile phone is the primary means of internet access, being a more affordable option in comparison to computer devices.

Table 4 illustrates the inequality in the digital skills levels of Internet users in Brazil. These results show that, both in 2014 and 2016, online communication is the domain with 
highest skills in all categories. Among the communication activities, the most frequent ones are sending messages via instant messaging applications (89\%) and use of social network sites $(76 \%)$. Both activities are the ones most often carried out by users of the upper classes and also those with less economic power.

Table 4. Digital Skills levels of Brazilian Internet Users (2014-2016)

\begin{tabular}{|c|c|c|c|c|c|c|c|c|}
\hline \multirow{2}{*}{ Digital Skills Domain } & \multicolumn{4}{|c|}{2014} & \multicolumn{4}{c|}{2016} \\
\cline { 2 - 10 } & $\bar{X}$ & $\%$ & SD & $\boldsymbol{\alpha}$ & $\bar{X}$ & $\%$ & SD & $\boldsymbol{\alpha}$ \\
\hline Operational [0-4] & 1.4 & 35.8 & 1.5 & 0.8 & 1.2 & 30.3 & 1.30 & 0.7 \\
\hline Informational [0-6] & 2.2 & 36.7 & 1.9 & 0.8 & 2.0 & 33.5 & 1.75 & 0.8 \\
\hline Communication [0-6] & 2.8 & 46.2 & 1.5 & 0.7 & 3.1 & 51.0 & 1.35 & 0.6 \\
\hline Content-Creation [0-3] & 1.3 & 42.7 & 1.0 & 0.7 & 1.2 & 40.7 & 0.99 & 0.6 \\
\hline
\end{tabular}

$\bar{X}=$ Sample Mean; $\%=$ percentage of activities performed by the Internet user in each digital skills domain; $\mathrm{SD}=$ sample standard-deviation; $\alpha=$ Cronbach's Alpha.

\section{$5 \quad$ Analyzing the effect of device divide in digital skills}

The OLS regression technique was used to understand the factors explaining the differences in digital skills levels of Internet users. The model included, as independent variables, the sociodemographic attributes and the combination of Internet access devices. For increased precision, the model used the metric variable of user age instead of the previously mentioned age group. Table 5 shows the four tested models, demonstrating the effect of the independent variables on each of the digital skills domains. Preliminary data inspection indicated problems of heteroscedasticity of the residuals. To overcome this problem, the Huber-White econometric procedure was used to estimate robust standard errors of the regression [30].

Table 5 summarizes the main results of the OLS regression with robust standard errors, presenting the standardized coefficients for each of the independent variables of the model. We decided to present the standardized coefficients in order to highlight the relative importance of each independent variable to the understanding of the dependent variables' behavior [29].

Table 5 shows a negative relation between the internet users age and their level of digital skills for the operational, communication and content creation domains, indicating that the older the age, the lower is the digital skills level. The only exception is the informational skills, as the more recent results (2016) did not evidence differences in the digital skills level based on the age attribute, although the 2014 data suggested a higher level of informational skills among older users. In summary, although younger users demonstrated superior performance in most skills, the findings allow us to question the premise of innate digital superiority of those users commonly classified as digital natives [26]. 
Table 5. Effect of sociodemographic factors and device divide in digital skills (standardized coefficients)

\begin{tabular}{|c|c|c|c|c|c|c|c|c|}
\hline & \multicolumn{2}{|c|}{ Operational } & \multicolumn{2}{|c|}{ Informational } & \multicolumn{2}{|c|}{ Communication } & \multicolumn{2}{|c|}{ Content-Creation } \\
\hline & 2014 & 2016 & 2014 & 2016 & 2014 & 2016 & 2014 & 2016 \\
\hline Age & $-0.21 * * *$ & $-0.26 * * *$ & 0.07 **** & 0.00 & $-0.06 * * *$ & $-0.08 * * *$ & $-0.13^{* * * *}$ & $-0.14 * * * *$ \\
\hline Gender (ref. Female) & & & & & & & & \\
\hline Male & $0.11 * * *$ & $0.18^{* * * *}$ & $-0.02 *$ & 0.01 & -0.01 & $-0.03 * * *$ & -0.01 & -0.01 \\
\hline Geographic Area (ref. Rural) & & & & & & & & \\
\hline Urban & $0.03^{* * *}$ & $0.02^{* * *}$ & $0.04^{* * *}$ & $0.05^{* * *}$ & $0.05^{* * * *}$ & $0.05^{* * *}$ & $0.03^{* * *}$ & $0.03^{* * *}$ \\
\hline Social Class (ref. Class A and B) & & & & & & & & \\
\hline Class C (middle class) & $-0.12 * * *$ & $-0.03 * * *$ & $-0.18 * * *$ & $-0.10 * * *$ & $-0.19 * * *$ & $-0.13 * * *$ & $-0.11 * * *$ & $-0.07^{* * * *}$ \\
\hline Class D and E (working classes) & $-0.13 * * *$ & $-0.05^{* * *}$ & $-0.16^{* * *}$ & $-0.14 * * *$ & $-0.16^{* * *}$ & $-0.15 * * *$ & $-0.12 * * *$ & $-0.09^{* * * *}$ \\
\hline $\begin{array}{l}\text { Device to access Internet (ref. } \\
\text { Only mobile) }\end{array}$ & & & & & & & & \\
\hline Only Computer & $-0.05 * * *$ & $-0.02 * * *$ & $0.06^{* * * *}$ & $0.02 * *$ & $-0.07 * * *$ & $-0.17 * * *$ & $-0.10^{* * * *}$ & $-0.09 * * *$ \\
\hline $\begin{array}{l}\text { Multiplatform (both computer } \\
\text { and mobile) }\end{array}$ & $0.20^{* * * *}$ & $0.21^{* * * *}$ & $0.32^{* * * *}$ & $0.34 * * *$ & $0.25^{\text {**** }}$ & $0.26^{* * * *}$ & $0,15 * * *$ & $0.17^{* * *}$ \\
\hline $\mathbf{R}^{2}$ & 0.16 & 0.17 & 0.17 & 0.17 & 0.17 & 0.19 & 0.10 & 0.09 \\
\hline
\end{tabular}

$(* * *) \mathrm{p}<0.01 ;(* *) \mathrm{p}<0.05 ;(*) \mathrm{p}<0.10 ;$

These results show that men presented a higher level of operational skills. On the other hand, in the other skills, there was little difference between men and women, suggesting the limitation of the gender attribute to explain differences in content-related skills. Regarding the geographic area, although the coefficients are statistically significant at $1 \%$, it has a small contribution in explaining differences in digital skills levels between urban and rural users.

The results for social class show the discriminatory effect of the socioeconomic attribute. Users with higher socioeconomic status (A and B), with higher income and schooling, are those with a higher level of digital skills. It confirms, therefore, the positive relation of social class with the digital skills identified in the literature. This result reinforces that positional inequalities affect the level of online competence of Internet users, indicating that previous off-line inequalities are maintained and amplified in the digital world [31].

The findings of Table 5 also show that those who access the Internet using both computer and mobile devices (multiplatform) have a higher level of digital skills, indicating that users that connect through both platforms can harness the specific advantages of each type of device, overcoming any limitations in their affordances, and increasing their digital skills[10].

The results also allow us to assess the differences in digital skills between mobile-only internet users and computer-only internet users, showing that those who access the Internet exclusively via mobile phone have a lower level of informational skills. These differences may be a result of both the amount of content made available for the mobile platform and the physical limitations of this type of device (e.g. small screen, limited typing functionality), which make searching and evaluating information more difficult and complex in mobile devices $[7,9,10,12]$. In contrast, computer-only Internet users have a lower level of operational, content creation and communication skills than those who access the Internet only via mobile devices.

Although contrary to the literature, our results indicate that the higher level of content creation skills among mobile-only users is related to the non-differentiation in terms of 
the depth and complexity of content produced. After all, even though both platforms enable the creation of online content, it is more challenging to develop complex content (e.g. software development) on mobile devices [10].

Although the literature points out that access via mobile devices is associated with leisure and entertainment activities, such as communication $[7,9,13]$, we understand that this positive relationship between the exclusive use of mobile and the ability to communicate can also be explained by the variety of applications available for digital communication, such as social networking applications (Facebook, Twitter, Instagram, etc.) and instant message exchange (WhatsApp, Telegram, Viber, Google Hangouts, etc.). In addition, some of these applications are targeted by zero-rating strategies of mobile operators, in which they do not charge for data consumed in such applications. Consequently, such "free" access encourages the use of these communication applications, especially among those with less economic power.

\section{$6 \quad$ Implications and Final Remarks}

The results of this research demonstrate that in Brazil, as in other developing countries, the mobile device plays an important role in the availability of Internet access, being used by more than $90 \%$ of Brazilian Internet users. However, while in groups with greater economic power, the mobile phone plays the role of complementary access, adding to other devices (e.g. desktop, laptop, tablet, game console, etc.), in more marginalized groups the mobile is a substitute device for computing equipment, evidencing the role of mobile leapfrogging among these users.

Regarding the effect of the device divide on digital skills, the results demonstrate that Internet users who access the Internet using both computational and mobile devices (multiplatform) are those with the highest level of digital skills. In contrast, those who connect exclusively via mobile displayed lower levels of informational skills due to the physical limitations of this device. Since this is a critical competence for Internet use, lack of informational skills can negatively impact the use of the web in capital-enhancing activities.

In terms of theoretical contribution, the findings of this research contribute to the studies that are based on the hypothesis of stratification, which states that previously existing social inequalities are maintained and amplified in the digital world [16,31]. After all, users with higher socioeconomic status connect through multiple devices, allowing to develop a higher level of digital competence. In contrast, users in lower-income groups (classes D and E) tend to connect only via mobile, developing lower level of digital skills. In general terms, these results demonstrate the existence of the Mathew Effect (the richer get richer and poor get poorer), refuting the thesis that digital exclusion would be a temporary phenomenon resulting from the diffusion of innovations.

In terms of managerial implications, the findings of this research suggest that public policies aimed at providing Internet access should seek to combine actions that stimulate both access via mobile devices, such as the provision of Internet access via open $\mathrm{Wi}-\mathrm{Fi}$ networks in public spaces, and also by providing connection via computers in public access centers (e.g. telecenters) and schools. In addition, the results suggest the need to promote training actions, focused on the development/enhancement (upskilling) of informational skills. 
The growing relevance of mobile devices for Internet access also leads to challenges to governments and businesses providing online content and services: due to the increasing percentage of mobile-only Internet users, especially in marginalized groups, it becomes critical to provide e-services in user-friendly interfaces adjusted to the mobile platform or via mobile applications, in order to facilitate online experience and engagement on the part of the users and overcome limitations in the affordances of the mobile. Finally, with the popularization of instant messaging applications (e.g. WhatsApp) and social networks sites in different social classes, we recommend the use of this type of application as communication channels for service delivery and interaction between government and citizens.

The main limitation of this research lies in the uniform characterization of mobile devices, not considering their wide variety in terms of technical capacity and functionality. Future studies could also explore the relationship between digital skills levels and their implications in terms of Internet use, as well as in terms of tangible outcomes achieved through the mobilization of such digital resources (access, skills and uses).

Acknowledgment. The author(s) received financial support from Coordenação de Aperfeiçoamento de Pessoal de Nível Superior - Brazil (CAPES) funding code 001.

\section{References}

1. ITU. Measuring the Information Society 2018 (Volume 1), https://www.itu.int/en/ITUD/Statistics/Documents/publications/misr2018/MISR-2018-Vol-1-E.pdf, last accessed feb. 2019

2. Dewan, S., Riggins, F. J.: The digital divide: current and future research directions. Journal of the Association for information systems 6(12), 13 (2005).

3. Hargittai, E.: The second-level digital divide: differences in people's online skills. First Monday, 7(4), (2002), http://firstmonday.org/ojs/index.php/fm/article/view/942, last accessed mar. 2017.

4. Van Dijk, J.: The deepening divide: Inequality in the information society. Thousand Oaks, Sage Publications (2005).

5. Scheerder, A., Van Deursen, A., Van Dijk, J.: Determinants of Internet skills, uses and outcomes. A systematic review of the second-and third-level digital divide. Telematics and Informatics, 34(8), 1607-1624 (2017).

6. Litt, E.: Measuring users' Internet Skills: a review of past assessments and a look toward the future. New Media \& Society, 15(4), 612-630 (2013).

7. Van Deursen, A., Van Dijk, J.: The first-level digital divide shifts from inequalities in physical access to inequalities in material access. New Media \& Society, 21(2), 354-375 (2019).

8. Humphreys, L., Von Pape, T., Karnowski, V.: Evolving mobile media: uses and conceptualizations of the mobile Internet. Journal of Computer-Mediated Communication, 18(4), 491-507 (2013).

9. Marler, W.: Mobile phones and inequality: findings, trends, and future directions. New Media \& Society, 20(9), 3498-3520 (2018).

10. Napoli, P. M., Obar, J. A.: The emerging mobile Internet underclass: a critique of mobile Internet access. The Information Society, 30(5), 323-334 (2014).

11. Mascheroni, G., Ólafsson, K.: The mobile Internet: Access, use, opportunities and divides among European children. New Media \& Society, 18(8), 1657-1679 (2016). 
12. Donner, J., Gitau, S., Marsden, G.: Exploring mobile-only Internet use: Results of a training study in urban South Africa. International Journal of Communication, 5, 574-597 (2011).

13. Pearce, K. E., Rice, R. E.: Digital divides from access to activities: Comparing mobile and personal computer Internet users. Journal of Communication, 63(4), 721-744 (2013).

14. Napoli, P. M., Obar, J. A.: Mobile leapfrogging and digital divide policy: assessing the limitations of mobile Internet access. Washington, D.C., New America Foundation (2013).

15. Mossberger, K., Tolbert, C. J., Hamilton, A.: Broadband adoption| measuring digital citizenship: mobile access and broadband. International Journal of Communication, 6, 2492-2528 (2012).

16. Dimaggio, P. et al.: Digital inequality: from unequal access to differentiated use. In: Neckerman, K. (ed.). Social Inequality. New York, Russell Sage Foundation (2004).

17. Hargittai, E.: An update on survey measures of web-oriented digital literacy. Social science computer review, 27(1), 130-137 (2009).

18. Potosky, D.: The Internet of knowledge (iKnow) measure. Computer in Human Behaviour, 23(6), 2760-2777 (2007).

19. Van Deursen, A., Helsper, E. J., Eynon, R.: Development and validation of the Internet Skills Scale (ISS). Information, Communication \& Society, 19(6), 804-823 (2016).

20. Gui, M., Argentin, G.: Digital skills of internet natives: Different forms of internet literacy in a random sample of northern Italian high school students. New Media \& Society, 13(6), 963-980 (2011).

21. Van Deursen, A., Van Dijk, J.: Improving digital skills for the use of online public information and services. Government Information Quarterly, 26(3), 333-340 (2009).

22. Van Deursen, A., Van Dijk, J.: Measuring Internet Skills. International Journal of Human-Computer Interaction, 26(10), 891-916 (2010).

23. Helsper, E. J., Eynon, R.: Distinct skill pathways to digital engagement. European Journal of Communication, 28(6), 696-713 (2013).

24. Van Dijk, J., Van Deursen, A.: Digital skills: unlocking the Information Society. London, Palgrave Macmillan, 2014.

25. Bunz, U.: A generational comparison of gender, computer anxiety, and computer-email-web fluency. Studies in Media and Information Literacy Education, 9(2), 54-69 (2009).

26. Hargittai, E.: Digital na(t)ives? Variation in internet skills and uses among members of the "net generation". Sociological inquiry, 80(1), 92-113 (2010).

27. Hilbert, M.: Digital gender divide or technologically empowered women in developing countries? A typical case of lies, damned lies, and statistics. Women's Studies International Forum, 34(6), 479-489 (2011).

28. CGI (Brazilian Internet Steering Committee): Survey on the Use of Information and Communication Technologies in Brazilian Households: ICT Households 2016. Sao Paulo, Brazilian Internet Steering Committee (2017).

29. Hair, J. F., Black, W. C., Babin, J. B., Anderson, R. E., Tatham, R. L.: Análise Multivariada de Dados. 6. ed. Porto Alegre, Bookman (2009).

30. Hayes, A. F., Introduction to Mediation, Moderation and Conditional Process Analysis: A regression-based approach. $2^{\text {nd }}$ ed. New York, Guilford Press (2018).

31. Zillien, N., Hargittai, E.: Digital distinction: Status-specific types of internet usage. Social Science Quarterly, 90(2), 274-291 (2009). 